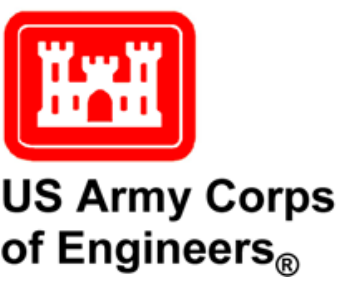

\title{
Wave Dissipation by Vegetation
}

\author{
by Mary E. Anderson, Jane McKee Smith, and S. Kyle McKay
}

PURPOSE: This Coastal and Hydraulics Engineering Technical Note (CHETN) provides a literature review of wave dissipation by vegetation.

INTRODUCTION: Flooding resulting from hurricanes and other extreme storm events is a prominent risk along the coasts. These coastal areas are typically of low elevation and relief, making land and infrastructure highly susceptible to inundation by storm surge and waves. The severity of this threat is exacerbated by sea level rise and a possible increase in storm frequency and strength due to climate change. Although hard protection structures such as levees and floodwalls reduce flood risk, these structures may fail when storm conditions exceed the design threshold. There is a general consensus that wetlands, which often serve as transition zones between open water and dry land, could act as buffers and reduce storm surge and propagating waves substantially before they encounter coastal development. Unfortunately, the capability of wetlands to serve as protection during extreme storms is not understood fully or well documented; furthermore, water level and wave height reductions by vegetation are studied only in low-energy environments. Nonetheless, these studies present methods to quantify vegetationinduced wave attenuation for both modeling and design. This technical note focuses on the damping of propagating water waves by vegetation, but also discusses surge reduction briefly. Although waves may be encountered in freshwater environments (e.g., boat wakes, lake fetch, flood waves, etc.), this review focuses on coastal vegetation and resultant effects on flood and storm damage reduction.

Water waves propagating through submerged and emergent vegetation lose energy by performing work on the vegetation stems, which directly results in smaller wave heights (Dalrymple et al. 1984). Wave attenuation by vegetation is a function of vegetation characteristics such as geometry, buoyancy, density, stiffness, and spatial coverage as well as wave conditions such as incident wave height, period, and direction. Vegetation-wave interactions are highly dynamic in that the vegetation field is exposed to variable wave forcing that changes with time as stems bend, flatten to the bed, or are washed out. As evidenced by these many dependencies and the extensive variety of coastal plants, the variability of wave damping by vegetation is large (Mendez and Losada 2004).

Dean and Bender (2006) applied linear wave theory in the shallow-water limit to show that wave setup, a component of storm surge resulting from the transfer of breaking wave momentum to the water column, is reduced by two-thirds in the presence of vegetation relative to conditions without vegetation. During Hurricanes Charley and Wilma, water levels recorded in two Florida mangrove ecosystems were reduced by as much as $9.4 \mathrm{~cm}$ per $\mathrm{km}$ inland. Although water levels were reduced as the surge moved through the coastal mangroves, the relative contribution of mangroves was still unclear (Krauss et al. 2009). Numerical simulations by Loder et al. (2009) and 
Wamsley et al. (2009) lend confidence to the potential of vegetation to reduce inundation on a landscape scale. However, model advancements are necessary since the influences of vegetation are often approximated as bottom friction.

\section{EXPERIMENTAL RESULTS OF WAVE DISSIPATION BY VEGETATION:}

Field Studies. The ability of coastal vegetation to dissipate wave energy is documented and quantified in numerous field studies focusing on low-energy environments. Field studies include those conducted along intertidal zones of England (Möller 2006, Cooper 2005, Möller and Spencer 2002, Möller et al.1999), coastal mangrove forests of Vietnam (Quartel et al. 2007, Mazda et al. 2006, Mazda et al. 1997), salt marshes of the United States (Bradley and Houser 2009, Knutson et al. 1982, Wayne 1976), a shallow lake in Sweden (Lövstedt and Larson 2010), and many others. Table 1 summarizes the dominant coastal plant species and the wave dissipation observed in these field experiments. High variability in wave attenuation is recorded in these limited studies as a result of different plant species, coverage, and wave conditions.

\section{Table 1. Field studies of wave attenuation over vegetation.}

\begin{tabular}{|c|c|c|c|}
\hline Reference & $\begin{array}{c}\text { Transect Length } \\
(\mathrm{m})\end{array}$ & Dominant Plant Species & $\begin{array}{c}\text { Average Wave Reduction } \\
\text { (\% per } \mathrm{m})\end{array}$ \\
\hline \multirow{2}{*}{ Wayne (1976) } & 20 & Spartina alterniflora & 3.6 \\
\hline & 20 & Thalassia testudinum & 2.1 \\
\hline Knutson et al. (1982) & 30 & Spartina alterniflora & 3.1 \\
\hline Möller et al. (1999) & 180 & $\begin{array}{l}\text { Limonium vulgare, Aster Tripolium, Atriplex } \\
\text { portulacoides, Salicornia spp., Spartina spp., } \\
\text { Suaeda maritime, Plantago maritime, } \\
\text { Puccinellia maritima }\end{array}$ & 0.34 \\
\hline \multirow{2}{*}{ Möller and Spencer (2002) } & 163 & $\begin{array}{l}\text { Aster, Suaeda, Puccinellia, Salicornia, } \\
\text { Limonium spp. }\end{array}$ & 0.54 \\
\hline & 10 & $\begin{array}{l}\text { Aster, Suaeda, Puccinellia, Salicornia, } \\
\text { Limonium spp. }\end{array}$ & 4.38 \\
\hline \multirow{3}{*}{ Cooper (2005) } & 300 & Puccinellia maritima, Salicorinia europaea & 0.30 \\
\hline & 250 & Atriplex portulacoides, Spartina alterniflora & 0.26 \\
\hline & 110 & Atriplex portulacoides, Salicorinia europaea & 0.71 \\
\hline \multirow{3}{*}{ Möller (2006) } & 10 & Spartina anglica, Salicornia spp. & 1.8 \\
\hline & 10 & Spartina anglica, Salicornia spp. & 1.4 \\
\hline & 10 & Salicornia spp. & 1.0 \\
\hline Quartel et al. (2007) & 100 & $\begin{array}{l}\text { Kandelia candel, Sonneratia sp., Avicennia } \\
\text { marina }\end{array}$ & 0.74 \\
\hline Bradley and Houser (2009) & 39 & Thalassia testudinum & 0.77 \\
\hline Lövstedt and Larson (2010) & $\begin{array}{l}\text { over first } 5-14 \mathrm{~m} \\
\text { of vegetation }\end{array}$ & Phragmites australis & $4.0-5.0$ \\
\hline
\end{tabular}

While earlier studies tend to quantify wave dissipation only within the vegetation (Knutson et al. 1982, Wayne 1976), later studies compare vegetated and unvegetated areas to emphasize the importance of maintaining and creating wetlands for coastal protection (Quartel et al. 2007, Mazda et al. 2006, Cooper 2005, Möller and Spencer 2002, Möller et al. 1999). A year-long study by Cooper (2005) found that wave attenuation over salt marshes was at least two times greater than over mudflats. The largest discrepancy along one transect was a wave height reduction of $0.30 \%$ per $\mathrm{m}$ across a salt marsh versus $0.03 \%$ per $\mathrm{m}$ across a mudflat. Attenuation over another UK salt marsh was approximately 50\% greater relative to a mudflat considering the same water depths (Möller et al. 1999). Coastal mangroves in the Red River Delta, Vietnam, were found to reduce wave heights 5-7.5 times more than bottom friction alone (Quartel et al. 2007). The other 
mentioned citations reflect similar results where attenuation was considerably greater over vegetation than bare transects.

Details of the pattern of wave attenuation as well as the behavior of the vegetation are of interest. Wave heights were observed to decay exponentially through vegetation beds with the most rapid reduction occurring within the first few meters of permanent vegetation cover. Knutson et al. (1982) reported a 20\% wave height reduction per $\mathrm{m}$ within the first $2.5 \mathrm{~m}$ while Möller and Spencer (2002) reported values of $1.14 \%$ and $2.12 \%$ per $\mathrm{m}$ within the first $10 \mathrm{~m}$ for two transects.

A recent study by Bradley and Houser (2009) characterized the relative movement of seagrass blades in oscillatory flow to address the importance of blade movement to wave attenuation. Wave attenuation tended to decrease as incident wave height increased and conditions became more turbulent (200< $\operatorname{Re}_{\mathrm{d}}<800$ where $\operatorname{Re}_{\mathrm{d}}$ is the stem Reynolds number defined as $\operatorname{Re}_{\mathrm{d}}=u_{c} d / v$ and $u_{c}$ is the characteristic velocity acting on the vegetation - typically the maximum horizontal velocity, $d$ is the plant width normal to the flow, and $v$ is kinematic viscosity). Video observations showed seagrass blades swaying over the entire wave cycle when exposed to lower orbital velocities. However, at higher orbital velocities, the blades extended in the direction of flow for the majority of the cycle and became streamlined, leading to reduced drag and less attenuation. The blades were also found to move in-phase with waves at a lower frequency $(0.38 \mathrm{~Hz})$ but out-of-phase with waves at the higher peak frequency $(0.67 \mathrm{~Hz})$. This behavior suggests higher frequencies (shorter wave periods) in a spectrum should experience more attenuation by seagrass; these results are supported by Lowe et al. (2007) who found that shorter-period waves penetrated more readily into a canopy of staggered plastic cylinders and were dissipated more effectively.

Lövstedt and Larson (2010) studied wave dissipation by reeds in a shallow lake. They analyzed changes in the wave height probability density function (PDF) for waves traveling through vegetation. It was expected that the Rayleigh distribution, which is often used to characterize random variation in wave height, would be transformed as higher waves were preferentially damped. Although a slight shift was observed toward the transformed PDF, especially in shallow water and for longer distances into the vegetation, the shift was not significant and merits additional attention.

Laboratory Studies. Vegetation-wave interactions have also been studied under controlled conditions in laboratory flume studies with either natural vegetation (Tschirky et al. 2000, Fonseca and Cahalan 1992) or artificial vegetation (Cavallaro et al. 2010, Augustin et al. 2009, Lima et al. 2006, Løvås and Tørum 2000, Dubi and Tørum 1996) simulated by various elements. The "vegetation" selected for each experiment is shown in Table 2. These flume experiments often isolate the influence of a single plant or wave property on wave dissipation by varying one parameter of interest while holding other parameters constant. Tschirky (2000) identified several trends with respect to wave attenuation through wetland plants:

1. total wave attenuation increased with longer plant beds,

2. higher stem densities resulted in greater attenuation,

3. attenuation slightly increased with larger incident wave heights,

4. attenuation varied inversely with water depth, and

5. no clear trend with respect to wave period was observed. 
ERDC/CHL CHETN-I-82

September 2011

\begin{tabular}{|c|c|}
\hline Reference & Element \\
\hline Cavallaro et al. (2010) & polyethylene Posidonia oceanica \\
\hline \multirow{2}{*}{ Augustin et al. (2009) } & cylindrical wooden dowels for Spartina alterniflora \\
\hline & polyethylene foam tubing for Spartina alterniflora \\
\hline Lima et al. (2006) & flexible nylon rope for Brachiaria subquadripara \\
\hline Løvås and Tørum (2000) & plastic Laminaria hyperborea \\
\hline Tschirky et al. (2000) & harvested Scirupus americanus \\
\hline Dubi and Tørum (1996) & plastic Laminaria hyperborea \\
\hline Fonseca and Cahalan (1992) & $\begin{array}{l}\text { harvested Halodule wrightii, Syringodium filiforme, Thalassia testudinum, } \\
\text { Zostera marina }\end{array}$ \\
\hline
\end{tabular}

Parametric analyses of wave attenuation through vegetation have been completed by a number of other authors with several supporting Tschirky's (2000) conclusions. Lima et al. (2006) reported attenuation values of $0.83-1.67 \%$ per $\mathrm{m}$ for $400 \mathrm{stems} / \mathrm{m}^{2}$ versus $5 \%$ per $\mathrm{m}$ for $600 \mathrm{stems} / \mathrm{m}^{2}$. Unlike the effect of stem density, the influence of wave height is less clear. The preliminary results of Cavallaro et al. (2010) also exhibit an increase in wave attenuation with larger incident wave height; however, Bradley and Houser (2009) observed less wave attenuation with increasing wave height. Løvås and Tørum (2000) found that although the smallest maximum wave height values were reduced the most, the largest difference between unvegetated and vegetated conditions was observed for the largest offshore wave heights.

A convenient way to address the single effect of water depth on wave attenuation is to define the relative stem length. The relative stem length represents the percentage of the water column occupied by the stem and is the ratio of stem length $\left(l_{s}\right)$ to water depth $(h)$. Augustin et al. (2009), Dubi and Tørum (1996), and Fonseca and Cahalan (1992) observed substantially more wave reduction under emergent conditions $\left(l_{s} / h \geq 1.0\right)$, with dissipation decreasing as water depth exceeded canopy height $\left(l_{s} / h<1.0\right)$. Based on theoretical and experimental results, Dubi and Tørum (1996) propose a 50\% reduction in significant wave heights over 74, 216, 495, and $1390 \mathrm{~m}$ for $l_{s} / h=0.50,0.33,0.25$, and 0.2 , respectively, for a stem density of $12 \mathrm{stems} / \mathrm{m}^{2}$. Augustin et al. (2009) observed 50-200\% greater wave attenuation per wave length over emergent than nearemergent $\left(l_{s} / h=0.75\right)$ stems. Field results of wave attenuation through mangroves reveal a slightly different pattern than that of seagrasses. Dissipation decreased as water exceeded the height of the pneumatophores (an extensive, hardy root system), similar to when water depth exceeded the height of the seagrass canopy. However, when the water level reached the height of the mangrove branches and leaves, the rate of wave reduction increased again (Mazda et al. 2006). Clearly the amount of wave dissipation is dependent on the plant structure (relative to the water depth). The value of $l_{s}$ may change over time as the water depth varies (due to tide or storm surge) or the vegetation flexes.

A relationship between relative vegetation height and wave dissipation is expected given that wave horizontal particle velocities, $u(z)$, are highest near the crest of the wave with velocities decreasing towards the bed (depending on water depth and wave period) (Dean and Dalrymple 1991). The highest velocities are impeded as stems approach the surface of the water, leading to greater drag and wave dissipation.

Intuitively, the impact of vegetation is greatest during emergent conditions where the entire velocity profile is impeded. As stems become submerged, the highest orbital velocities pass over the canopy. Only slower wave velocities occurring over the lower part of the water column are 
impeded, thus, less drag is generated, which translates to less wave attenuation. An illustration of emergent and submerged conditions is presented in Figure 1. Wetlands may be less effective in attenuating waves during storm events due to submergence, but Fonseca and Cahalan (1992) suggest that even a relatively low rate of wave reduction across wetlands can be substantial when applied over long distances.

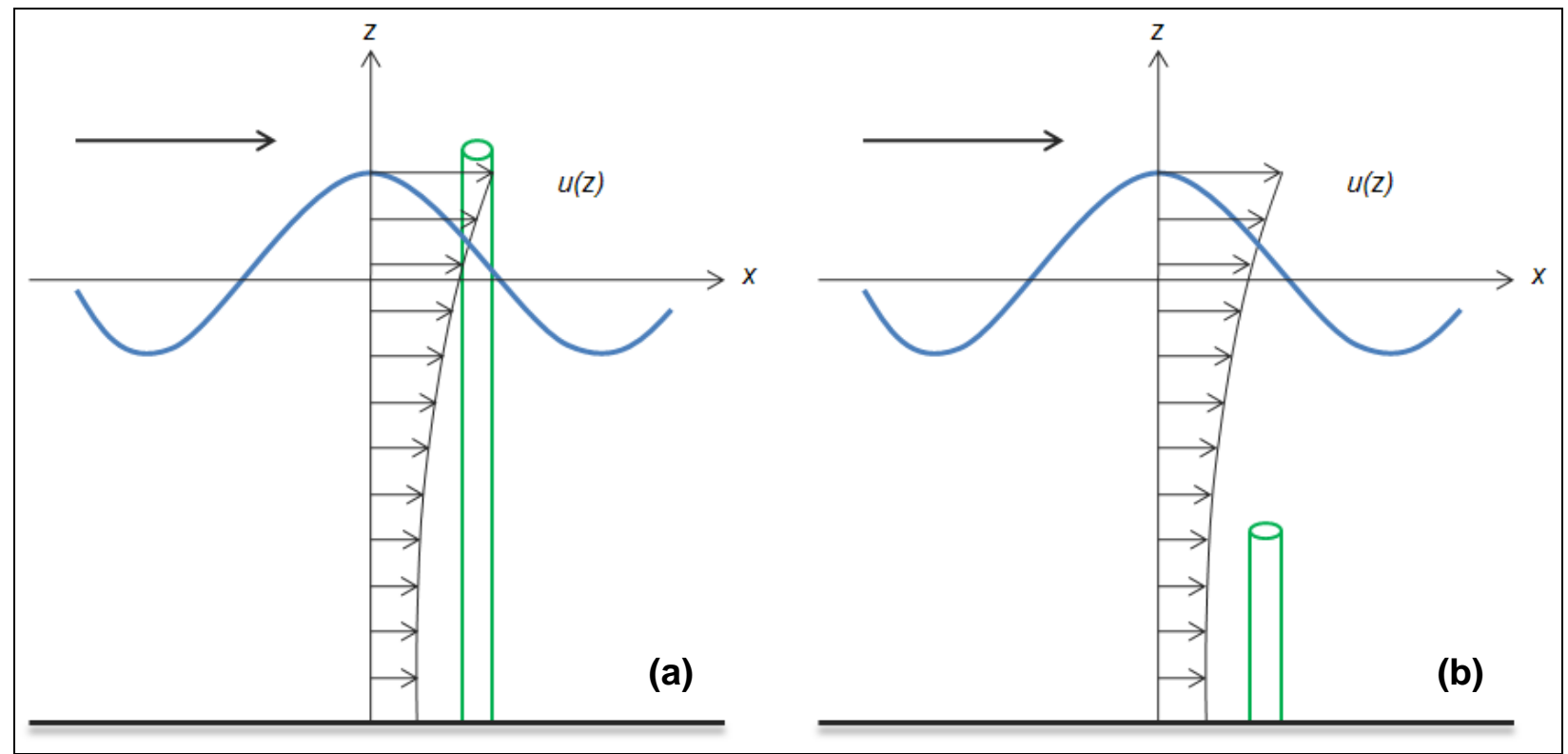

Figure 1. Interactions of particle velocities with emergent (a) and submerged (b) stems.

In comparison to the other parameters, the effect of wave period on dissipation is the most contradictory and unresolved. Möller et al. (1999) observed salt marshes reducing wave energy at all frequencies by the same degree. However, other field and laboratory studies indicate a dominating frequency-dependent component to wave attenuation over vegetation. As previously mentioned, Bradley and Houser (2009) and Lowe et al. (2007) both describe seagrass as a lowpass filter in which higher frequency components are dissipated more effectively. Cavallaro et al. (2010) and Fonseca and Cahalan (1992) address wave period by defining the relative water depth $(h / L)$ where $L$ is wave length. This representation allows the investigation of wave period as a function of water depth, which determines whether a wave is shallow water $(h / L<0.05)$, intermediate $(0.05<h / L<0.5)$, or deepwater $(h / L>0.5)$ (Sorensen 2006). Wave attenuation decreased as waves approached the deepwater regime for both Cavallaro et al. (2010) and Fonseca and Cahalan (1992).

Shallow-water and deepwater waves have different particle trajectories, and these trajectories affect the amount of drag generated and wave energy dissipated. Diagrams of particle trajectories for shallow-water and deepwater waves are shown in Figure 2. The particle path for a deepwater wave is a circular orbit that decays exponentially with negligible particle motion at an elevation below the surface $>-0.5 \mathrm{~L}$. The horizontal excursion for a shallow-water wave is constant over depth but the vertical excursion decreases linearly from the surface to zero at the bottom, resulting in an elliptic orbit (Sorenson 2006, Dean and Dalrymple 1991). The interaction of waves with vegetation can vary with relative depth (or wave period), and it is anticipated that vegetation will affect shallow-water waves more than deepwater waves because shallow waves tend to have larger 
velocities throughout the water column and near the bed. It is important to note that waves interact with the bottom based on relative depth, so waves with longer wave lengths become shallow-water waves and interact with the bottom at deeper depths (Koch et al. 2006).

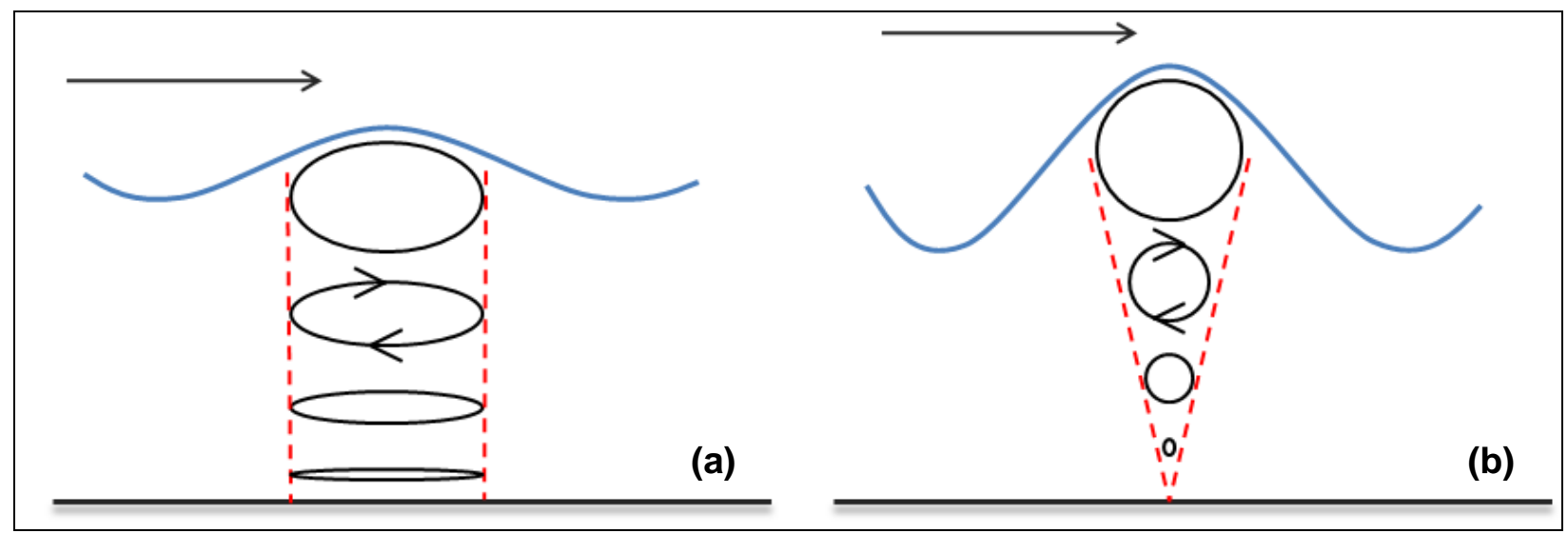

Figure 2. Particle trajectories for shallow-water (a) and deepwater (b) waves (Dean and Dalrymple 1991).

MODELING WAVE-VEGETATION INTERACTIONS: Various models and model extensions for wave-vegetation interactions have been proposed. While some models approximate vegetation with higher bottom friction factors (Camfield 1977, Möller et al. 1999), the majority implement an empirical drag coefficient to estimate the wave-induced drag forces along the plant stem (Dalrymple et al.1984, Asano et al.1992, Kobayashi et al.1993, Mendez and Losada 1999, Mendez and Losada 2004, Lima et al. 2006, Lowe et al. 2007, Mullarney et al. 2010). Massel (1999) and Vo-Luong (2008) focus exclusively on modeling the interactions between propagating water waves and mangroves. Applying these models to appropriate physical conditions, based on the biomechanics of the plant species, is crucial. For example, reed plants such as S. alterniflora can be simulated as rigid, vertical cylinders whereas flexible vegetation such as kelp requires a more complex drag formulation. Figure 3 is a diagram of typically used parameters in wave-vegetation modeling, where $\Delta s$ is average stem spacing, $d$ is average stem diameter, $l_{s}$ is average stem length, $N$ is the average number of stems per unit area (average stem density, stems $/ \mathrm{m}^{2}$ ), $F_{X}$ is total horizontal force per unit volume on a stem array, and $h$ is water depth.

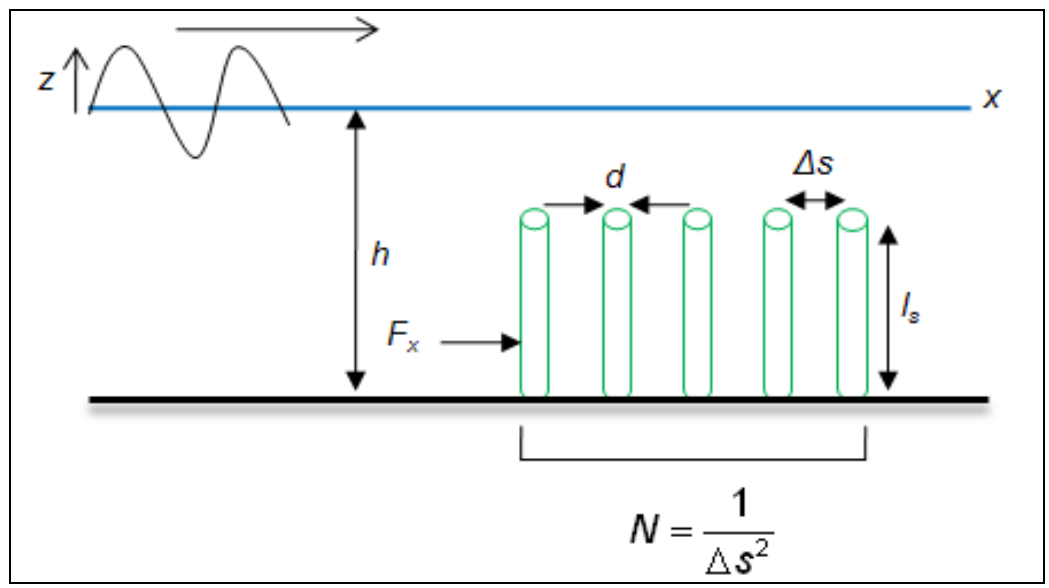

Figure 3. Vegetation modeling parameters (modified from Dean and Bender 2006). 
One of the first hydrodynamic models for wave attenuation was proposed by Dean (1979) based on empirical estimates of fluid drag forces acting on vertical, rigid cylinders. The model for the damping of incident wave height $\left(H_{o}\right)$ by coastal plants was the following:

$$
\frac{H}{H_{o}}=\frac{1}{1+A^{\prime} x}
$$

where

$$
A^{\prime}=\frac{C_{D} d}{6 \pi \Delta s^{2} h} H_{o}
$$

$H$ is the local wave height. $x$ is the cross-shore distance waves propagate through the vegetation field (Figure 3), and $A$ ' is the rate of wave energy dissipation. This form of equation $\left(H / H_{o}\right)$ is used by several authors with differing dissipation rate formulations. The bulk or average drag coefficient $C_{D}$ for the entire plant field was assumed to be constant over the depth and was approximated as 1.0 to describe the forces associated with smooth, rigid cylinders. Knutson et al. (1982) recognized that the Dean model did not describe the responses of plants to wave forcing, such as swaying, and incorporated an empirical plant drag coefficient, $C_{P}$, to account for the difference between rigid cylinders and plants,

$$
\frac{H}{H_{o}}=\frac{1}{1+A^{\prime \prime} x}
$$

where

$$
A^{\prime \prime}=\frac{C_{p} C_{D} d}{6 \pi \Delta s^{2} h} H_{o}
$$

A calibrated value of $C_{P}=5$ minimized the error between predicted and measured wave heights for data collected in $S$. alterniflora marshes of Chesapeake Bay.

Dalrymple et al. (1984) formulated an algebraic dissipation equation using linear wave theory and conservation of wave energy by approximating a vegetation bed as an array of rigid, vertical cylinders. Wave dissipation is assumed to only be a function of the horizontal drag force per unit volume (inertial component neglected), which is summed over all the stems and is expressed as,

$$
F_{x}=\frac{1}{2} \rho C_{D} N d u|u|
$$

where $u$ is the horizontal fluid velocity due to wave motion and $\rho$ is the fluid density. The timeaveraged energy dissipation resulting from vegetation is the product of $F_{x}$ and $u$, and is integrated over the stem length. The solution for wave height in a vegetation field was given by:

$$
\frac{H}{H_{o}}=\frac{1}{1+\alpha x}
$$


where

$$
\alpha=\frac{1}{3 \pi} C_{D} N d\left(\sinh ^{3} k l_{s}+3 \sinh k l_{s}\right)\left[\frac{4 k}{3 \sinh k h(\sinh 2 k h+2 k h)}\right] H_{o}
$$

and $k$ is the wave number. The model accounts for arbitrary water depth and stem length, allowing for both submerged and emergent vegetation, and the bulk drag coefficient $C_{D}$ is empirically determined to account for varying responses of different plant species to wave forcing (i.e., calibrated to different plant structure or flexibility). Mendez and Losada (2004) expanded upon Dalrymple et al. (1984) and developed an empirical model to estimate monochromatic and random wave transformations over mildly-sloping vegetation fields under nonbreaking and breaking conditions. The random wave expansions were validated for the artificial Laminaria hyperborea kelp experiments of Dubi (1995) and Løvås (2000) for nonbreaking and breaking waves, respectively.

Kobayashi et al. (1993) derived an analytical solution based on the continuity and linearized momentum equations for small-amplitude monochromatic wave attenuation over submerged vegetation. The continuity equation within the vegetation was given by,

$$
\frac{\partial u}{\partial x}+\frac{\partial w}{\partial z}=0
$$

and the linearized momentum equations per unit water volume was expressed as,

$$
\begin{aligned}
& \rho \frac{\partial u}{\partial t}=-\frac{\partial p}{\partial x}-F_{x} \\
& \rho \frac{\partial w}{\partial t}=-\frac{\partial p}{\partial z}-F_{z}
\end{aligned}
$$

where $w$ is vertical particle velocity, $z$ is the vertical coordinate, $t$ is time, $F_{z}$ is the total vertical force per unit volume, and $p$ is dynamic pressure. Like Dalrymple et al. (1984), plant stems are approximated as vertical cylinders, and $F_{z}$ is assumed negligible $\left(\mathrm{F}_{\mathrm{z}} \approx 0\right)$ when compared to $F_{X}$. However, while Dalrymple et al. (1984) implements a quadratic drag formulation, Kobayashi et al. (1993) linearizes the horizontal drag force as a function of fluid particle velocity. The local wave height is assumed to decay exponentially with propagation through a vegetation bed according to the following form:

$$
\frac{H}{H_{o}}=\exp \left(-k_{i} x\right)
$$

where $k_{i}$ is the exponential damping coefficient. Calibrated values of $C_{D}$ are obtained by matching calculated values of the normalized decay coefficient, $k_{i}^{\prime}=k_{i} h$, to measured $k_{i}^{\prime}$ values. The exponential decay solution captured adequately the wave trends observed by Asano et al. (1988). 
Asano et al. (1992) refined the analytical solution developed by Kobayashi et al. (1993) to include small amplitude vegetation motion. A more correct estimation of $F_{x}$ is calculated using the relative velocity $\left(u_{r}\right)$ between the horizontal particle velocity and swaying velocity of the stem $\left(u_{v}\right)$,

$$
F_{x}=\frac{1}{2} \rho C_{D} N d u_{r}\left|u_{r}\right|
$$

where $u_{r}=\left(u-u_{v}\right)$. The drag force is then linearized as in Kobayashi et al. (1993). Each individual stem was modeled as a cantilever beam, fixed at the bottom, with swaying modeled as a forced vibration with one degree of freedom where buoyancy and stiffness are the restoring forces. The solution of this problem is determined iteratively and indicated by a converged solution. Comparisons between the present model and the results of Asano et al. (1988) yielded a better agreement than the solution of Kobayashi et al. (1993). The wave decay solutions of Kobayashi et al. (1993) and Asano et al. (1992) are further extended by Mendez and Losada (1999). The complete wave field is included by separating the system into four regions (region seaward of the vegetation, region above the vegetation, region behind the vegetation, and within the vegetation) and obtaining a velocity potential for each region by solving the boundary value problem. This method accounts for reflection and transmission of waves as they encounter the interfaces between the seaward, vegetation, and leeward regions. Mendez and Losada (1999) describe $F_{x}$ in its entirety using a linear summation of the drag force and inertial force, which is caused by fluid and vegetation accelerations,

$$
F_{x}=\frac{1}{2} \rho C_{D} N d u_{r}\left|u_{r}\right|+\rho N d t_{v}\left[\frac{C_{m} \partial u}{\partial t}-\left(C_{m}-1\right) \frac{\partial^{2} \zeta}{d t^{2}}\right]
$$

where $t_{v}$ is the stem width, $C_{m}$ is the inertia coefficient, and $\zeta$ is the horizontal displacement of the vegetation stand with respect to the vertical axis. The model solution compared well with the experimental results of Asano et al. (1988) and captured accurately the modulation in wave heights resulting from reflection at the vegetation interfaces. The formulation was then extended to irregular waves, and model results compared well to Dubi (1995).

Lima et al. (2006) formulated an algebraic model for monochromatic wave damping over highly flexible vegetation (nylon string) using nonlinear stream function wave theory. Unlike the previously discussed models where $F_{x}$ is simply a summation of the drag contributed by individual stems, the resistances resulting from interactions between stems, such as entangling, is accounted for using an ensemble interaction coefficient $(\tau)$. The horizontal drag force in which all stem elements are identical is defined as,

$$
F_{x}=\tau N F_{x}^{1}
$$

where $F_{x}^{1}$ is the force exerted by a single stem on the fluid. Each nylon string is treated as a string of equally spaced nodes with freedom of movement in the $x-z$ plane, and is described by a system of three equations; a constitutive equation, and the momentum balances in the horizontal and vertical directions. The solution of the system provides the connecting forces between nodes and 
the horizontal and vertical displacement of each node. The velocity and acceleration of individual stems were determined from video and allowed $C_{D}$ to be best fit according to the expression,

$$
F_{T}=\frac{1}{2} \rho C_{D} A_{s} u_{r}\left|u_{r}\right|
$$

where $F_{T}$ is the hydrodynamic forcing and $A_{S}$ is the area of the stem normal to the relative velocity. According to Newton's Law, the resisting force $F_{x}^{1}$ of the stem against the flow equals in magnitude the force $F_{T}$ exerted by the flow on the stem. The drag force for a single element is then obtained as a function of flow and plant properties by dimensional analysis,

$$
F_{x}^{1}=0.133 \frac{\rho_{v} d\left(\frac{l_{s}}{h}\right)^{4} H^{3}}{T^{2}}
$$

where $\rho_{v}$ is the density of the vegetation element and $T$ is wave period. Following calibration with single elements, the ensemble coefficient and wave decay model are derived from the behavior of the stem field. The ensemble coefficient is given as,

$$
\tau=7.44 \frac{L^{2} d^{3 / 2}}{H_{o} l_{s}^{2} \Delta s^{1 / 2}}
$$

Substituting $\tau$, the wave height decay model for waves traveling through a vegetation field with flexible elements is the following:

$$
\frac{H}{H_{o}}=\frac{1}{1+\beta x}
$$

where

$$
\beta=7.916 \frac{L^{2}\left(\frac{l_{s}}{h}\right)^{4} d^{5 / 2} N^{5 / 4}}{g T^{2}(4 n-1) l_{s}^{2}} \frac{\rho_{v}}{\rho}
$$

and $n$ is the ratio between wave group speed and celerity given as (Dean and Dalrymple 1991),

$$
n=1+\frac{2 k h}{\sinh 2 k h}
$$

Lima et al. (2006) concluded that the resistance imposed by a group of stems was on average four times higher than summing individual forces for all stems, and suggested that stem interactions are of a greater importance than previously thought.

Mullarney et al. (2010) derived an analytical solution for the wave-forced movement of singlestem vegetation and compared the results against observed motion of Schoenoplectus americanus. 
The majority of measured relationships between water and stem motion were in good agreement with model theory. Theoretical analyses identified stiffness as an important parameter influencing wave attenuation. Low stiffness stems moved with the surrounding water; in contrast, stiffer stems led the surrounding water by $90^{\circ}$ and have little mobility. Mullarney et al. (2010) defined stiffness using vegetation biomechanical and wave properties; low stiffness is associated with a low Young's modulus, long thin stems, and high-energy, high-frequency waves. Simulated dissipation predicted for flexible stems was approximately $30 \%$ that of rigid stems.

VEGETATION DRAG COEFFICIENTS: The hydrodynamic forces acting on the vegetation due to waves is $F=\left(F_{x}, 0, F_{z}\right)$, where it is usually assumed that $F_{z}$ is negligible in comparison to $F_{x}$ (shallow water). The horizontal force $F_{x}$ is described typically using a Morison-based equation. The Morison equation describes the forces induced by a solid body in oscillatory flow and is comprised of two parts: a drag force $\left(F_{D}\right)$ and an inertial force $\left(F_{I}\right)$. The Morison equation is given as,

$$
F=F_{D}+F_{1}=1 / 2 \rho \tilde{C}_{D} A|u| u+\rho C_{m} V \frac{\partial u}{\partial t}
$$

where $\tilde{C}_{D}$ is the drag coefficient for a singular element, $A$ is the cross-sectional area of the body perpendicular to the flow, and $V$ is the body's volume (Morison et al. 1950). The values of the drag and inertia coefficients are determined by experiments. In the case of a cylinder of diameter $d$ is oscillatory flow, the reference area per unit length is $A=d$. Only the drag force is considered in the majority of the above models, and an average or bulk drag coefficient $C_{D}$ serves as the calibration parameter to minimize error between measured and predicted wave heights. The bulk drag coefficient allows for the total drag force on a vegetation field to be a summation of the drag forces contributed by individual stems.

Defining a generalized value to describe all plant-induced drag is impossible since $C_{D}$ is highly dependent on hydrodynamic and plant characteristics. However, the generalized behavior of the vegetation bulk drag coefficient can be understood by examining empirical formulas. These empirical equations attempt to predict appropriate $C_{D}$ values for specific plant types by defining $C_{D}$ as a function of nondimensional flow parameters.

One parameter found to influence the bulk drag coefficient is the stem Reynolds number,

$$
\operatorname{Re}_{\mathrm{d}}=\frac{u_{c} d}{v}
$$

To calculate the stem Reynolds number, Kobayashi et al. (1993) substituted the maximum horizontal velocity given by linear theory for $u_{c}$,

$$
u_{\max }=\frac{g H k}{2 \omega} \frac{\cosh k(h+z)}{\cosh k h}
$$

where $\omega$ is wave angular frequency and defined as $\omega=(2 \pi / T)$. Kobayashi et al. (1993) plotted CD values calibrated for the artificial kelp experiments of Asano et al. (1988) against the 
corresponding stem Reynolds number and found the following relationship for 2,200 < Red < 18,000:

$$
C_{D}=0.08+\left(\frac{2200}{\operatorname{Re}_{\mathrm{d}}}\right)^{2.4}
$$

The bulk drag coefficient decreases with increasing $\mathrm{Re}_{\mathrm{d}}$ and approaches the order of 0.1 for large $\mathrm{Re}_{\mathrm{d}}$. Mendez et al. (1999), who extended the model of Kobayashi et al. (1993) to include vegetation motion and interfaces, also used Asano et al. (1988) data for model validation. However, the empirical relationships vary from that proposed by Kobayashi et al. (1993) and differ based on whether vegetation motion is considered,

Swaying neglected:

$$
C_{D}=0.08+\left(\frac{2200}{\operatorname{Re}_{\mathrm{d}}}\right)^{2.2} \text { for } 200<\mathrm{Re}_{\mathrm{d}}<15,500
$$

Swaying considered:

$$
C_{D}=0.40+\left(\frac{4600}{\mathrm{Re}_{\mathrm{d}}}\right)^{2.9} \text { for } 2300<\mathrm{Re}_{\mathrm{d}}<20,000
$$

The "no swaying” equation proposed by Mendez et al. (1999) yielded a 20\% improvement in the correlation coefficient over that of Kobayashi et al. (1993) and resulted in less scatter. These relationships compared with Kobayashi et al. (1993) are presented in Figure 4. It is clear that the inclusion of plant motion results in a larger bulk drag coefficient given the same stem Reynolds number. This occurs because the characteristic velocity substituted into the drag formulation is smaller when considering plant motion. Kobayashi et al. (1993) neglected swaying and substituted maximum horizontal particle velocity given by linear wave theory while Mendez at al. (1999) substituted the relative velocity between the fluid and plant. This relative velocity is smaller than that given by linear wave theory and, therefore, a higher value of $C_{D}$ is required to obtain the same amount of attenuation.

Mendez and Losada (2004) attempted to parameterize $C_{D}$ for the artificial kelp experiments of Dubi (1995) as a function of the local Keulegan-Carpenter number, $K$, defined as,

$$
K=\frac{u_{c} T}{d}
$$

The maximum velocity $u_{c}$ for random waves was defined using the root-mean-square wave height $H_{r m s}$ and peak wave period $T_{p}$. However, Mendez and Losada (2004) observed scatter when $C_{D}$ was considered to be a function of $K$ alone and found that the drag coefficient also depended on the relative stem length. To allow $C_{D}$ to be a function of $K$ and the relative stem length, a modified Keulegan-Carpenter number $(Q)$ was defined and the relationship between $C_{D}$ and $Q$ was defined as the following for $7 \leq Q \leq 172$ : 


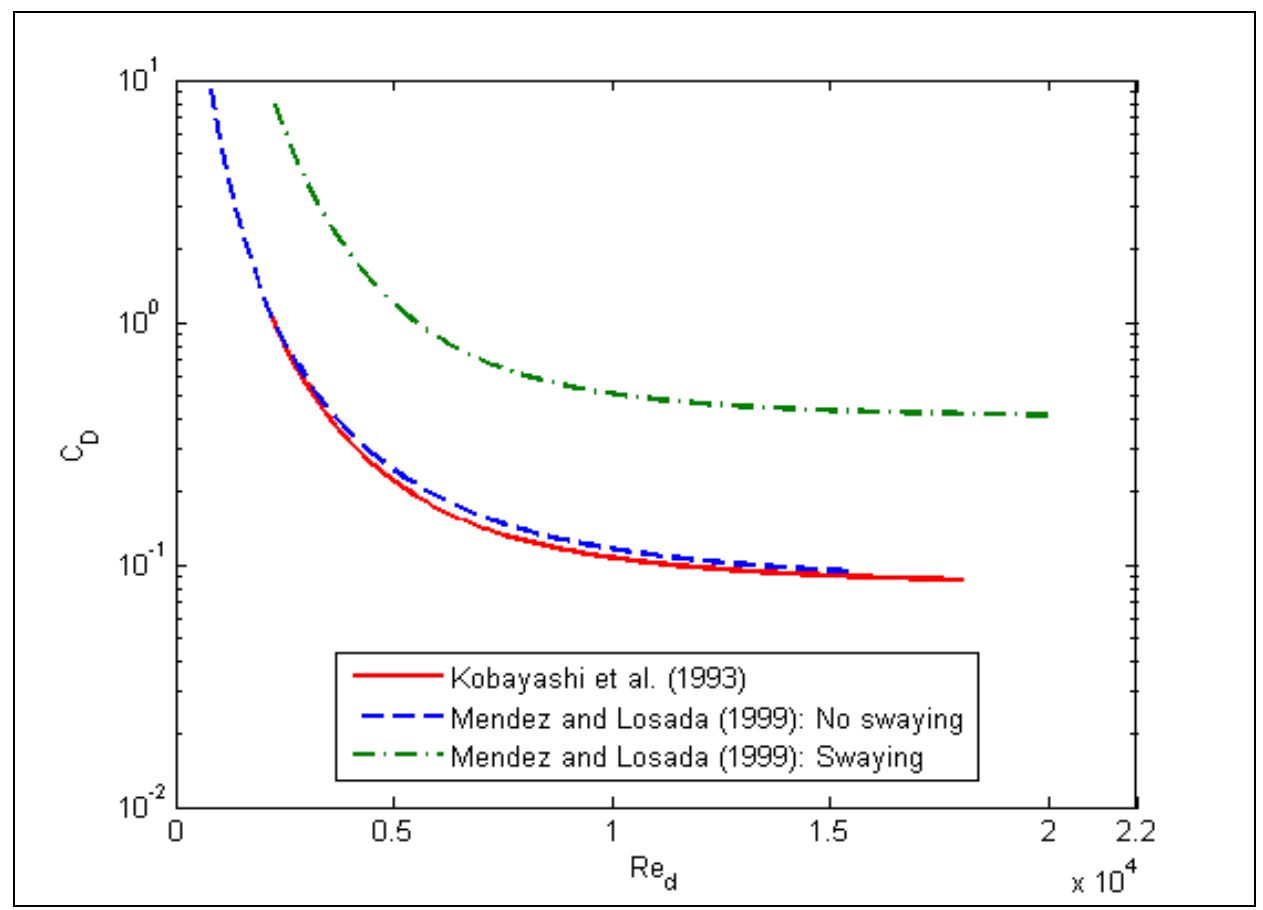

Figure 4. Empirical relationships between $\mathrm{Re}_{\mathrm{d}}$ and $C_{D}$.

$$
C_{D}=\frac{\exp (-0.0138 Q)}{Q^{0.3}}
$$

where

$$
Q=\frac{K}{\left(l_{s} / h\right)^{0.76}}
$$

The bulk drag coefficient decreases with increasing $K$ and increases with larger relative stem lengths given the same Keulegan-Carpenter number. An increase in the drag coefficient with higher relative stem length is expected since a larger percentage of the water column is occupied by the plant. This trend can be seen in Figure 5. Augustin et al. (2009) found $C_{D}$ was better correlated with the stem Reynolds number during emergent conditions and the Keulegan-Carpenter number during near-emergent conditions. However, Bradley and Houser (2009) found no improvement in parameterizing $C_{D}$ with the Keulegan-Carpenter number versus the stem Reynolds number.

Hydrodynamic studies with steady unidirectional flows and vegetation suggest interactions between cylinders also affect the bulk drag coefficient. Nepf (1999) found that $C_{D}$ decreased as stem density increased as a result of turbulence-scale wake sheltering. Wake sheltering is an interaction between upstream and downstream cylinders whereby upstream stem wakes reduce the drag on downstream stems. Variations in vegetation geometry and spatial coverage might also change the attenuation capacity of a vegetation field. Future controlled studies investigating how stem spatial variation, and hence turbulence flow fields and vortex interactions, relate to wave attenuation are recommended Irish et al. (2008). 


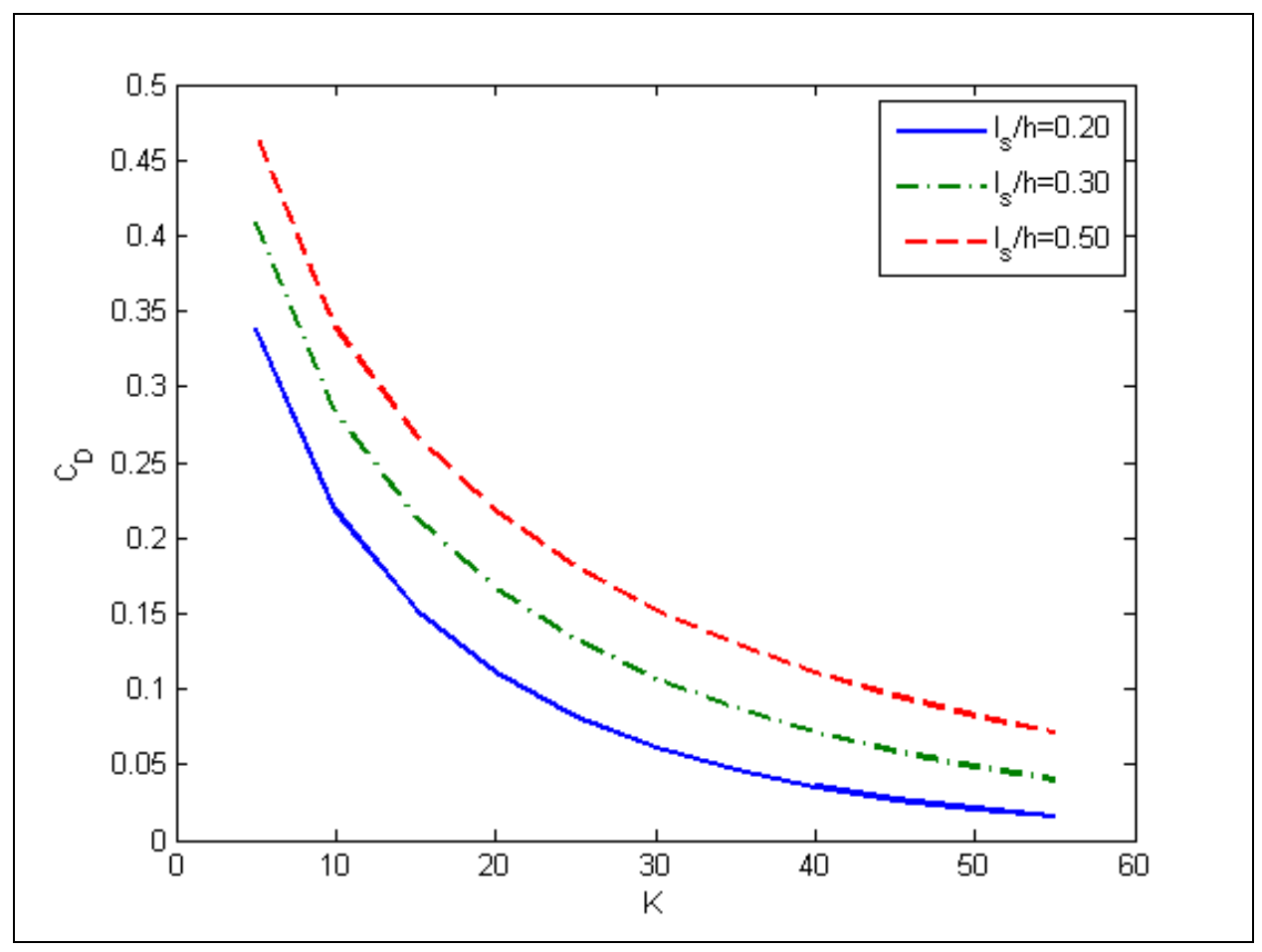

Figure 5. $\quad C_{D}$ as a function of $\mathrm{K}$ and relative stem length.

Myrhaug et al. (2009) outlines a practical method for estimating the drag force on a vegetation field subjected to nonlinear random waves. This is achieved using a common drag formulation and the empirical relationships for $C_{D}$ proposed by Mendez et al. (1999). Like the other formulations, wave-induced drag forces are described using a Morison-type equation with vegetation motion and inertial forces neglected where the maximum horizontal drag force within a wave cycle is given by,

$$
F_{\max }=\frac{1}{2} \rho C_{D} N d u_{\max }^{2}
$$

The relationships proposed by Mendez et al. (1999) are of the following form:

$$
C_{D}=\alpha+\left(\frac{\beta}{\operatorname{Re}_{d}}\right)^{\gamma}
$$

where for rigid plants,

$$
(\alpha, \beta, \gamma)=(0.08,2200,2.2) \text { for } 200<\operatorname{Re}_{\mathrm{d}}<15,500
$$

and for swaying plants,

$$
(\alpha, \beta, \gamma)=(0.40,4600,2.90) \text { for } 2300<\operatorname{Re}_{\mathrm{d}}<20,000
$$


Nonlinear wave effects are taken into account using Stokes second-order wave theory. Stochastic and deterministic methods to determine the drag coefficient are presented, although Myrhaug et al. (2009) emphasize using the stochastic method. An estimate for the root-mean-square drag coefficient is the following:

$$
C_{D r m s}=r \sqrt{B}\left(1+k_{p} a_{r m s} \frac{s A}{r B}\right)
$$

where $k_{p}$ is the wave number associated with the spectral peak and $a_{r m s}$ is the root-mean-square wave amplitude. The other variables $\left(s, r, A, B, R_{r m s}\right)$ are given as,

$$
\begin{gathered}
s=\frac{3 \sinh k_{p} l_{s}}{2 k_{p} \cosh ^{2} k_{p} h \sinh ^{3} k_{p} h}\left(1+\frac{2}{3} \sinh ^{2} k_{p} l_{s}\right) \\
r=\frac{1}{2 \cosh ^{2} k_{p} h}\left(\frac{1}{2 k_{p}} \sinh 2 k_{p} l_{s}+l_{s}\right) \\
A=\alpha^{2} \Gamma(3.5)+2 \alpha\left(\frac{\beta}{R_{r m s}}\right)^{\gamma} \Gamma\left(3.5-\frac{\gamma}{2}\right)+\left(\frac{\beta}{R_{r m s}}\right)^{2 \gamma} \Gamma(3.5-\gamma) \\
B=\alpha^{2} \Gamma(3)+2 \alpha\left(\frac{\beta}{R_{r m s}}\right)^{\gamma} \Gamma\left(3-\frac{\gamma}{2}\right)+\left(\frac{\beta}{R_{r m s}}\right)^{2 \gamma} \Gamma(3-\gamma) \\
R_{r m s}=\frac{d a_{r m s} \omega_{p}}{v} \frac{\cosh k_{p} l_{s}}{\sinh k_{p} h}
\end{gathered}
$$

and $\omega_{p}$ is the spectral peak angular frequency and $\Gamma$ is the gamma function. It should be noted that the analytical results of Myrhaug et al. (2009) have not been compared to experimental datasets and should be used with caution.

VEGETATION MORPHOLOGY: As discussed, drag coefficients are often used as lumped calibration parameters accounting for different vegetation types, material properties, and morphologies. In actuality, individual plants respond to varying environmental conditions and adjust their morphology and structure accordingly. Intra- and inter-species competition then governs community structure and composition. These individual, population, and community level processes vary over space and time to result in a patchy landscape of variable hydraulic roughness. This section reviews ongoing mechanisms and processes briefly at each of these scales of analysis and the resulting effects on wave attenuation. Complex feedback mechanisms also exist between the wave environment altering vegetation; however, these are beyond the scope of this review (See Koch et al. 2006 for review).

At the individual level, vegetation effects on hydrodynamics are the result of plant material properties, surface textures, and architecture. The primary material property of interest is the 
rigidity or flexibility of the plant material, often reported as Young's modulus of elasticity (Ghisalberti and Nepf 2002, Freeman et al. 2000). Of particular interest in wave environments is the material density or specific gravity, which determines an individual's buoyancy and location in the water column (Koch et al. 2006). Skin friction of plant material varies with leaf and stem conditions, and in some cases exposed roots also contribute (e.g., mangrove swamps). Lastly, individuals adjust their above-ground and below-ground architecture depending on ambient environmental conditions such as light or soil density. Above-ground architecture manifests through changes in canopy shape, frontal area, plant height, and many other measures of plant structure. Although rooting conditions do not influence wave attenuation directly, they control an individual's susceptibility to bending and washout (Peltola 2006), which both play key roles in determining frictional forces (Fonseca et al. 1982).

Plant community composition and structure varies widely owing to spatially and temporally variable environments, competition between individuals of a given species, competition between species, and interactions with the faunal community (e.g., herbivory). Coastal vegetation assemblages vary from stands of near monocultural composition (e.g., mangroves, invasive phragmites) to diverse communities with many taxa (i.e., groups of plants, Figure 6). Although community composition is well-acknowledged as an important factor influencing wave attenuation, to date, there have been few studies examining multiple taxa simultaneously. Moreover, the density and spatial arrangement of the community has been demonstrated to be an influential driver of wave attenuation (Tanino and Nepf 2008, Nepf 1999).
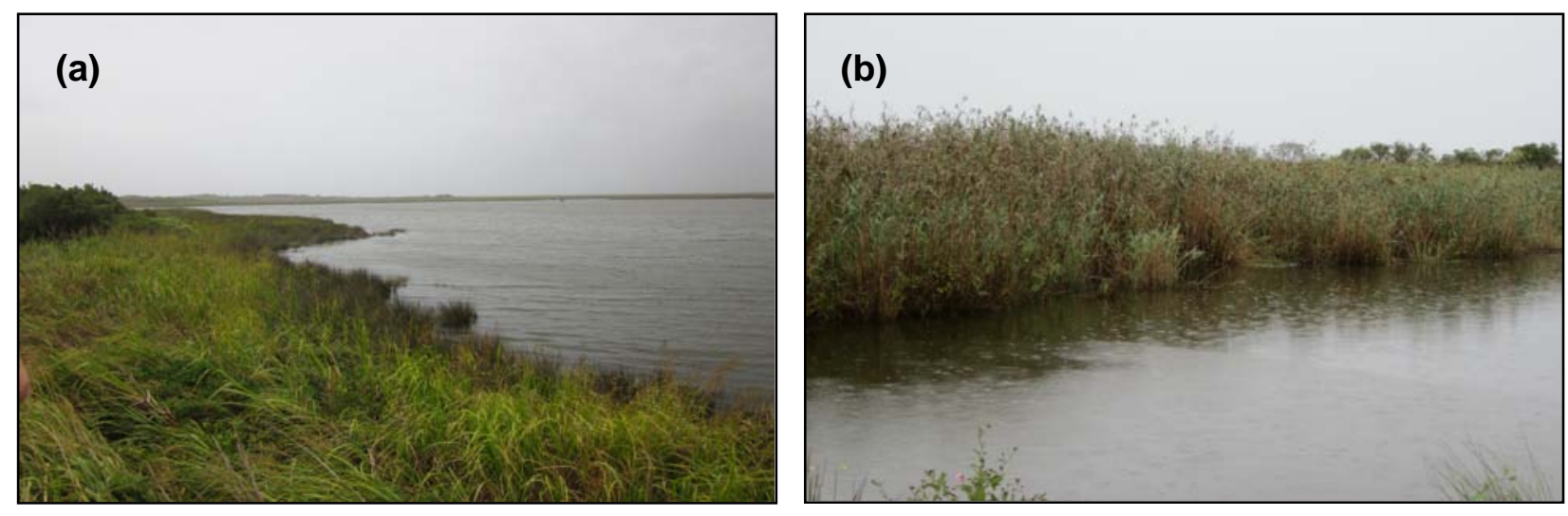

Figure 6. Two marsh plant communities in Currituck Sound, NC: (a) a diverse assemblage composed of Juncus romerianus, Spartina spp., and numerous other taxa and (b) a near monospecific stand of Phragmites australis.

In addition to complex individual, population, and community level processes, spatial and temporal variability in abiotic (e.g., chemical or physical) conditions can influence vegetation morphology, and as a result, its effects on wave attenuation. In a flume study of riverine shrubs, Jarvela (2002) observed that leaf-on conditions could produce double the friction force of leafoff conditions for the same species. The magnitude, frequency, duration, and timing of disturbances (e.g., erosion events, herbicide application, low light conditions) can also lead to changes in morphology or community structure such as vegetation washout or scouring, age structuring, or differential growth rates. Table 3 provides a few examples of individual, community, and spatio-temporal processes affecting wave attenuation in four common coastal ecosystem types. 


\section{Table 3. Examples of the influence of individual, community, and spatio-temporal dynamics on wave attenuation by common coastal plant communities.}

\begin{tabular}{|c|c|c|c|}
\hline $\begin{array}{c}\text { Coastal Plant } \\
\text { Community }\end{array}$ & Individual Prope & Community Properties & Spatio-Temporal Dynamics \\
\hline $\begin{array}{l}\text { Macroalgae } \\
\text { (e.q. kelp) }\end{array}$ & $\begin{array}{l}\text { Seaweed fronds becoming more } \\
\text { slender as they increase in size } \\
\text { (Gaylord and Denny 1997) }\end{array}$ & $\begin{array}{|lcr|}\text { Seaweed } & \text { fronds } & \text { "recline" } \\
\text { against each } & \text { other to } \\
\text { withstand high } & \text { velocity } \\
\text { (Denny and Gaylord 2002) }\end{array}$ & $\begin{array}{l}\text { Kelp buoyancy inducing stem } \\
\text { tension at high depths (Denny } \\
\text { and Gaylord 2002) }\end{array}$ \\
\hline $\begin{array}{l}\text { Submerged aquatic } \\
\text { vegetation } \\
\text { (e.g., eelgrass) }\end{array}$ & $\begin{array}{l}\text { Seagrass bending in } r \\
\text { increased velocity (Fon } \\
\text { 1982) }\end{array}$ & $\begin{array}{l}\text { Natural row alignment of } \\
\text { seagrasses in response to } \\
\text { flow directionality (Fonseca } \\
\text { et al. 2007) }\end{array}$ & $\begin{array}{l}\text { Distribution of seagrass beds is } \\
\text { often due to hydrodynamic } \\
\text { disturbance (Koch et al. 2006) }\end{array}$ \\
\hline $\begin{array}{l}\text { Marsh } \\
\text { yrass) }\end{array}$ & $\begin{array}{l}\text { Differences in plant morphology of } \\
\text { Spartina alterniflora, Juncus } \\
\text { roemerianus, and Ditichlis spicata } \\
\text { result in different velocity profiles } \\
\text { (Leonard and Luther 1995) }\end{array}$ & $\begin{array}{l}\text { Increased bulrush density } \\
\text { reduced wave transmission } \\
\text { in both field and laboratory } \\
\text { tests (Tschirky 2000) }\end{array}$ & $\begin{array}{lll}\text { Wetland vegetation } & \text { plays } \\
\text { different roles in wave } & \text { setup } \\
\text { depending upon water } & \text { depth } \\
\text { (Irish et al. 2008) } & \end{array}$ \\
\hline Forestec & $\begin{array}{l}\text { Exposed rooting zone of } \\
\text { mangroves inducing high frictional } \\
\text { resistance at low water levels } \\
\text { (Massel et al. 1999) }\end{array}$ & $\begin{array}{l}\text { Mangrove density impacts } \\
\text { the role of wave breaking on } \\
\text { overall attenuation (Vo- } \\
\text { Luong and Massel 2008) }\end{array}$ & $\begin{array}{l}\text { Mangrove swamps create } \\
\text { asymmetric tidal currents and } \\
\text { sustain tidal channels (Wolanski } \\
\text { 1992) }\end{array}$ \\
\hline
\end{tabular}

This combination of individual, community, and spatio-temporal processes alters wave attenuation through two primary parameters: area exposed to flow and drag. As reviewed by Fischenich and Dudley (2000), area may be measured through a variety of means depending on the analytical roughness formulation required. As shown in previous sections, drag is often lumped together analytically because of the numerous confounding variables and processes. This CHETN has reviewed drag formulations extensively with respect to wave attenuation; however, the reader is encouraged to examine the numerous formulations from riverine literature (e.g., Fischenich 2000, Freeman et al. 2000, Kees et al. 2010, McKay and Fischenich 2011). Furthermore, vegetative roughness in rivers has been accounted for historically with calibrated photographic approaches (e.g., pictorial comparison in Barnes 1967 and Arcement and Schneider 1989), an approach not yet applied to coastal environments.

CONCLUSIONS: The ability of coastal plants to dissipate wave energy and wave heights in low-energy environments is demonstrated and documented in both field and laboratory studies. Wave attenuation is highly dependent on the plant biomechanical and wave characteristics, as evidenced by the high variability in wave attenuation, and generalizing vegetation-wave behavior is extremely difficult. Capturing the wave transformations induced by vegetation is critical for predicting coastal hydrodynamics accurately, and modeling these transformations is required to quantify the benefits of vegetation for storm damage reduction. This has lead to the development of a number of wave-vegetation hydrodynamic formulations, which account for the influence of plant structure on wave attenuation through a calibration variable, often $C_{D}$, that is adjusted to minimize the difference between predicted and observed wave heights. These models, and the datasets they are calibrated with, help further our understanding of wave attenuation by wetlands, and serve as the foremost methods in describing vegetative dissipation in coastal modeling and planning. However, a number of knowledge gaps still exist:

- Quantifying the impact of stem interactions (based on spacing and structure/randomness of plants)

- Validating existing dissipation formulations for storm conditions (large waves and surge)

- Quantifying the role of wave period on dissipation over a wide range of depths and periods 
- Determining drag coefficients based on wave and plant parameters instead of through calibration

- Including seasonal impacts on dissipation potential

- Bridging the gap between the larger scale at which wave models are applied (meters to hundreds of meters) and the much smaller scale of the plant features and dissipation

- Determining when vegetation lays over, breaks off, or uproots and thus becomes ineffective to dissipate waves

- Quantifying the role of community composition (i.e., composition and configuration of multiple species of plants) in vegetative roughness

- Validating formulations in combined wave and current environments

- Determining the interaction of wave nonlinearity and dissipation for shallow depths

Existing studies of wave dissipation by vegetation provide a range of analytical, empirical, and numerical models, but current methods require calibration and application within the narrow range of available lab and field data. Future studies need to expand the range of the data as well as generalize model formulations.

\section{SYMBOLS:}

$A$

$A_{s}$

$a_{r m s}$

$C_{D}$

$C_{\text {Drms }}^{D}$

$C_{m}$

$C_{P}$

$d$

$F_{D}$

$F_{I}$

$F_{\text {max }}$

$F_{T}$

$F_{X}$

$F_{x}^{1}$

$F_{Z}$

$h$

H

$H_{O}$

$H_{r m s}$

$k$

K

$k_{i}$

$k_{i}^{\prime}$

$k_{p}$

$L$

$l_{S}$ cross-sectional area of the body perpendicular to the flow

area of stem normal to relative velocity

root-mean-square wave amplitude

empirical bulk drag coefficient

drag coefficient for a singular element

root-mean-square drag coefficient

inertial coefficient

empirical plant coefficient

average plant stem diameter

drag force

inertial force

maximum horizontal drag force within a wave cycle

hydrodynamic forcing

horizontal force per unit volume on a stem array

force exerted by a single stem on the fluid

vertical force per unit volume on a stem array

water depth

local wave height

incident wave height

root-mean-square wave height

wave number

Keulegan-Carpenter number

exponential damping coefficient

normalized exponential damping coefficient

wave number associated with spectral peak

wave length

average plant stem length 


$\begin{array}{ll}N & \text { plant stem density } \\ n & \text { ratio between group speed and celerity } \\ p & \text { dynamic pressure } \\ Q & \text { modified Keulegan-Carpenter number } \\ \operatorname{Re}_{\mathrm{d}} & \text { stem Reynolds number } \\ t & \text { time } \\ T & \text { wave period } \\ T_{p} & \text { peak wave period } \\ t_{v} & \text { stem width } \\ u & \text { horizontal wave particle velocity } \\ u_{c} & \text { characteristic velocity acting on the vegetation } \\ u_{m a x} & \text { maximum horizontal velocity within a wave cycle } \\ u_{r} & \text { relative velocity between } u_{v} \text { and } u \\ u_{v} & \text { stem swaying velocity } \\ V & \text { body's volume perpendicular to the flow } \\ w & \text { vertical wave particle velocity } \\ X & \text { cross-shore propagation distance through a vegetation field } \\ Z & \text { vertical coordinate } \\ \Gamma & \text { gamma function } \\ \Delta s & \text { average stem spacing } \\ \zeta & \text { horizontal displacement of the vegetation stand } \\ v & \text { kinematic viscosity } \\ \rho & \text { fluid density } \\ \rho_{v} & \text { density of vegetation element } \\ \tau & \text { ensemble interaction coefficient } \\ \omega & \text { wave angular frequency } \\ \omega_{p} & \text { peak spectral angular frequency } \\ Z & \text { vertical coordinate } \\ & \end{array}$

ADDITIONAL INFORMATION: This CHETN was prepared as part of the Wave Dissipation by Vegetation for Coastal Protection work unit in the Flood and Coastal Systems R\&D Program and was written by Mary E. Anderson (Mary.Anderson@usace.army.mil) and Jane Smith (Jane.M.Smith@usace.army.mil) of the U.S. Army Engineer Research and Development Center (ERDC), Coastal and Hydraulics Laboratory (CHL) and S. Kyle McKay (Kyle.McKay@usace.army.mil) of the ERDC Environmental Laboratory (EL). The Program Manager is Mr. William Curtis. This CHETN should be cited as follows:

Anderson, M.E., J.M. Smith,, and S.K. McKay. 2011. Wave Dissipation by Vegetation. Coastal and Hydraulics Engineering Technical Note ERDC/CHL CHETN-I-82. Vicksburg, MS: U.S. Army Engineer Research and Development Center. http://chl.erdc.usace.army.mil.chetn.

\section{REFERENCES:}

Arcement, G. J. and V. R. Schneider. 1989. Guide for selecting Manning's roughness coefficients for natural channels and floodplains. USGS-WSP-2339. Denver, CO: United States Geological Survey. 
Asano, T., S. Tsutsui, and T. Sakai. 1988. Wave damping characteristics due to seaweed. Proceedings of the $35^{\text {th }}$ Coastal Engineering Conference in Japan. JSCE. 138-142 (in Japanese).

Asano, T., H. Deguchi, and N. Kobayashi. 1992. Interactions between water waves and vegetation. Proceedings of the $23^{\text {rd }}$ International Conference on Coastal Engineering. ASCE. 2710-2723.

Augustin, L.N., J.L. Irish, and P. Lynett. 2009. Laboratory and numerical studies of wave damping by emergent and near-emergent wetland vegetation. Coastal Engineering. 56(3): 332-340.

Barnes, H.H. 1967. Roughness characteristics of natural channels. USGS WSP-1849. Washington, DC: United States Geological Survey.

Bradley, K., and C. Houser. 2009. Relative velocity of seagrass blades: Implications for wave attenuation in lowenergy environments. Journal of Geophysical Research. 114: F01004.

Camfield, F.E. 1977. A method for estimating wind-wave growth and decay in shallow water with high values of bottom friction. CETA 77-6. Fort Belvoir, VA: Coastal Engineering Research Center.

Cavallaro L., C.L. Re, G. Paratore, A. Viviano, and E. Foti. 2010. Response of Posidonia oceanic to wave motion in shallow-waters: Preliminary experimental results. Proceedings of the $32^{\text {nd }}$ International Conference on Coastal Engineering. Coastal Engineering Research Council. 1-10.

Cooper, N.J. 2005. Wave dissipation across intertidal surfaces in the Wash Tidal inlet, Eastern England. Journal of Coastal Research. 21(1): 28-40.

Dalrymple, R.A., J.T. Kirby, and P.A. Hwang. 1984. Wave diffraction due to areas of energy dissipation. Journal of Waterway, Port, Coastal, and Ocean Engineering. 110(1): 67-79.

Dean, R.G. 1979. Effects of vegetation on shoreline erosional processes. Wetland Function and Values: The State of Our Understanding. 1: 415-426.

Dean, R.G., and R.A. Dalrymple. 1991. Water Wave Mechanics for Engineers and Scientist. World Scientific Publishing. Singapore.

Dean, R.G., and C.J. Bender. 2006. Static wave setup with emphasis on damping effects by vegetation and bottom friction. Coastal Engineering. 53: 149-156.

Denny, M. and B. Gaylord. 2002. The mechanics of wave-swept algae. The Journal of Experimental Biology. 205: 1355-1362.

Dubi, A. 1995. Damping of water waves by submerged vegetation: A case study on Laminaria hyperborea. PhD thesis. University of Trondheim, the Norwegian Institute of Technology, Trondheim, Norway.

Dubi, A., and A. Tørum. 1996. Wave energy dissipation in kelp vegetation. Proceedings of the $25^{\text {th }}$ International Conference on Coastal Engineering. ASCE. 2626-2639.

Fischenich, C. 2000. Resistance due to vegetation. ERDC TN-EMRRP-SR-07. Vicksburg, MS: Waterways Experiment Station.

Fischenich, C. and S. Dudley. 2000. Determining drag coefficients and area for vegetation. ERDC TN-EMRRP-SR08. Vicksburg, MS: Waterways Experiment Station.

Fonseca, M.S., J.S. Fisher, J.C. Zieman, and G.W. Thayer. 1982. Influence of seagrass, Zostera marina L., on current flow. Estuarine, Coastal, and Shelf Science. 15: 351-364.

Fonseca, M.S., and J.A. Cahalan. 1992. A preliminary evaluation of wave attenuation by four species of seagrass. Estuarine, Coastal, and Shelf Science. 35(6): 565-576.

Fonseca, M.S., M.A.R. Koehl, and B.S. Kopp. 2007. Biomechanical factors contributing to self-organization in seagrass landscapes. Journal of Experimental Marine Biology and Ecology. 340: 227-246.

Freeman, G.E., W.J. Rahmeyer, and R.R. Copeland. 2000. Determination of resistance due to shrubs and woody vegetation. ERDC/CHL TR-00-25. Vicksburg, MS: Engineer Research and Development Center. 
Gaylord, B. and M.W. Denny. 1997. Flow and flexibility: I. Effects of size, shape and stiffness in determining wave forces on the stipitate kelps Eisenia arborea and Pterygophora californica. The Journal of Experimental Biology. 200: 3141-3164.

Ghisalberti, M. and H.M. Nepf. 2002. Mixing layers and coherent structures in vegetated aquatic flows. Journal of Geophysical Research. 107 (C2), doi: 10.1029/2001JC000871.

Irish, J.L. L.N. Augustin, G.E. Balsmeier, and J.M. Kaihatu. 2008. Wave dynamics in coastal wetlands: A state-ofknowledge review with emphasis on wetland functionality for storm damage reduction. Shore and Beach. 76(3): 52-56.

Jarvela, J. 2002. Flow resistance of flexible and stiff vegetation: A flume study with natural plants. Journal of Hydrology. 269: 44-54.

Kees, C.E., M.W. Farthing, S.A. Mattis, and C.N. Dawson. 2010. Homogenization and upscaling of flow through vegetation. XVIII International Conference on Water Resources CMWR 2010, Barcelona.

Knutson, P.L., R.A. Brochu, W.N. Seelig, and M. Inskeep. 1982. Wave damping in Spartina alterniflora marshes. Wetlands. 2(1): 87-104.

Kobayashi, N., A.W. Raichle, and T. Asano. 1993. Wave attenuation by vegetation. Journal of Waterway, Port, Coastal, and Ocean Engineering. 119(1): 30-48.

Koch, E.W., L.P. Sanford, S.N. Chen, D.J. Shafer, and J.M. Smith. 2006. Waves in seagrass systems: Review and technical recommendations. ERDC TR-06-15. Vicksburg, MS: Engineering Research and Development Center.

Krauss, K.W., T.W. Doyle, T.J. Doyle, C.M. Swarzenski, A.S. From, R.H. Day, and W.H. Conner. 2009. Water level observations in mangrove swamps during two hurricanes in Florida. Wetlands. 29(1): 142-249.

Leonard, L.A. and M.E. Luther. 1995. Flow hydrodynamics in tidal marsh canopies. Limnology and Oceanography. 40 (8): 1474-1484.

Lima, S.F., C.F. Neves, and N.M.L. Rosauro. 2006. Damping of gravity waves by fields of flexible vegetation. Proceedings of the 30 ${ }^{\text {th }}$ International Conference on Coastal Engineering. World Scientific. 491-503.

Loder, N.M., J.L. Irish, M.A. Cialone, and T.V. Wamsley. 2009. Sensitivity of hurricane surge to morphological parameters of coastal wetlands. Estuarine, Coastal, and Shelf Science. 84: 625-636.

Løvås, S.M. 2000. Hydro-physical conditions in kelp forests and the effect on wave damping and dune erosion: A case study on Laminaria hyperborea. PhD thesis. University of Trondheim, the Norwegian Institute of Technology, Trondheim, Norway.

Løvås, S.M., and A. Tørum. 2000. Effect of submerged vegetation upon wave damping and run-up on beaches: A case study of Laminaria hyperborea. Proceedings of the $27^{\text {th }}$ International Conference on Coastal Engineering. ASCE. 851-864.

Lövstedt, C.B., and M. Larson. 2010. Wave damping in reed: Field measurements and mathematical modeling. Journal of Hydraulic Engineering. 136(4): 222-233.

Lowe, R.J., J.L. Falter, J.R. Koseff, S.G. Monismith, and M.J. Atkinson. 2007. Spectral wave flow attenuation within submerged canopies: Implications for wave energy dissipation. Journal of Geophysical Research. 112: C05018.

Massel, S.R., K. Furukawa, and R.M. Brinkman. 1999. Surface wave propagation in mangrove forests. Fluid Dynamics Research. 24(4): 219-249.

Mazda, Y., M. Magi, M. Kogo, and P.N. Hong. 1997. Mangroves as a coastal protection from waves in the Tong King delta, Vietnam. Mangroves and Salt Marshes. 1(2): 127-135.

Mazda, Y., M. Magi, Y. Ikeda, T. Kurokawa, and T. Asano. 2006. Wave reduction in a mangrove forest dominated by Sonneratia sp. Wetlands Ecology and Management. 14(4): 365-378.

McKay, S.K. and J.C. Fischenich. 2011. Robust prediction of hydraulic roughness. ERDC/CHL CHETN-VII-11. Vicksburg, MS: Engineer Research and Development Center. 
Méndez, F.J., I.J. Losada, and M.A. Losada. 1999. Hydrodynamics induced by wind waves in a vegetation field. Journal of Geophysical Research. 104(C8): 18383-18396.

Méndez, F.J. and I.J. Losada. 2004. An empirical model to estimate the propagation of random breaking and nonbreaking waves over vegetation fields. Coastal Engineering. 51(2): 103-118.

Möller, I., T. Spencer, J.R. French, D.J. Leggett, and M. Dixon. 1999. Wave transformation over salt marshes: A field and numerical modelling study from North Norfolk, England. Estuarine, Coastal, and Shelf Science. 49(3): 411-426.

Möller, I., and T. Spencer. 2002. Wave dissipation over macro-tidal saltmarshes: Effects of marsh edge typology and vegetation change. Journal of Coastal Research. S136: 506-521.

Möller, I. 2006. Quantifying saltmarsh vegetation and its effect on wave height dissipation: Results from a UK east coast saltmarsh. Estuarine, Coastal, and Shelf Science. 69: 337-351.

Morison, J.R., M.P. O’Brien, J.W. Johnson, and S. Schaaf. 1950. The force exerted by surface waves on piles. Petroleum Transactions. 189: 149-154.

Mullarney, J.C., and S.M. Henderson. 2010. Wave-forced motion of submerged single-stem vegetation. Journal of Geophysical Research. 115: C12061.

Myrhaug, D., L.E. Holmedal, and M.C. Ong. 2009. Nonlinear random wave-induced drag force on a vegetation field. Coastal Engineering. 56(3): 371-376.

Nepf, H.M. 1999. Drag, turbulence, and diffusion in flow through emergent vegetation. Water Resources Research. 35(2): 479-489.

Peltola, H.M. 2006. Mechanical stability of trees under static loads. American Journal of Botany. 93(10): 15011511.

Quartel, S., A. Kroon, P.G.E.F. Augustinus, P. Van Santen, and N.H. Tri. 2007. Wave attenuation in coastal mangroves in the Red River Delta, Vietnam. Journal of Asian Earth Sciences. 29(4): 576-584.

Sorensen, R.M. 2006. Basic Coastal Engineering. Springer Science. New York.

Tanino, Y. and H.M. Nepf. 2008. Laboratory investigation of mean drag in a random array or rigid, emergent cylinders. Journal of Hydraulic Engineering. 134 (1): 34-41.

Tschirky, P., K. Hall, and D. Turcke. 2000. Wave attenuation by emergent wetland vegetation. Proceedings of the $27^{\text {th }}$ International Conference on Coastal Engineering. ASCE. 865-877.

Vo-Luong, P., and S.R. Massel. 2008. Energy dissipation in non-uniform mangrove forests of arbitrary depth. Journal of Marine Systems. 74: 603-622.

Wamsley, T.V., M.C. Cialone, J.M. Smith, J.H. Atkinson, and J.D. Rosati. 2009. The potential of wetlands in reducing storm surge. Ocean Engineering. 37: 59-68.

Wayne, C.J. 1976. The effects of sea and marsh grass on wave energy. Coastal Research Notes. 4(7): 6-8.

Wolanski, E. 1992. Hydrodynamics of mangrove swamps and their coastal waters. Hydrobiologia. 247: 141-161.

NOTE: The contents of this technical note are not to be used for advertising, publication, or promotional purposes. Citation of trade names does not constitute an official endorsement or approval of the use of such products. 